\title{
Performance Analysis of DC-DC Converter with Grid Connected Bidirectional Inverter
}

\author{
M.Srikanth ${ }^{\# 1}$, Dr.Poonam Upadhyay ${ }^{* 2}$, Dr S. Tarakalyani ${ }^{\# 3}$ \\ ${ }^{1}$ Assistant Professor in EEE Department, KL University, Vaddeswaram, Guntur, India. \\ sikanth_ee250@kluniversity.in \\ 2 Professor in EEE Department, VNRVJIET, Bachupally, Hyderabad \\ poonampu@yahoo.com, \\ ${ }^{3}$ Professor in EEE Department, JNTUH, Hyderabad. \\ tarakalyani@gmail.com
}

Abstract - Now a days DC-DC converter plays a vital role in power industries to regulate the DC voltage. This paper focuses on comparison between the Grid Connected Single-Phase Bidirectional Inverter with Boost Maximum Power Point Tracker (MPPT) and Buck /Boost MPPT. In boost MPPT DC-DC converter always boost-up the given solar power, occasionally the inverter suffers from as high-voltage stress as the open voltage of the arrays. To reduce this limitation, an MPPT topology, which combines buck and boost converters is proposed [1], in which the control algorithm for tracking maximum power points is based on a perturbation and observation method. By using PV system and DC-DC boost converter with MPPT generate power that power utilized by the dc applications. Whenever surplus power is available then that power is sold to grid, whenever solar irradiation is below the set value, power can be brought from grid, a bidirectional inverter is required to control the power flow between dc bus and ac grid. By using MATLAB/Simulation results are analysed.

Keyword- Photovoltaic system, MPPT, boost converter, Buck/Boost converter, bidirectional inverter, gridconnection and unipolar PWM switching, Grid connection(GC), Power factor correction (PFC), perturbation \& observe (P\&O).

\section{INTRODUCTION}

Energy crisis inevitably brings nearer for the depletion of fossil. The greenhouse effect becomes more serious by the increased requirements for electric power. In recent years, renewable energy has received great attention due to the advantages of clean, no pollution and huge reserves. Many distributed generations such as photovoltaic cells, wind turbines and fuel cells have been linked with the utility grids [2]. To reduce conversion losses and supply high quality power, a dc microgrid is proposed [3]. Power electronic converters are one of the most important devices among the components of the microgrid [3]. The design of bi-directional inverters has been researched recently [4]. A bi-directional converter is designed to regulate the dc bus voltage for several types of energy sources and energy storage. The functions of the bi-directional inverter include grid connection mode and power factor correction mode. If the renewable energy is greater than the load requirement, the bidirectional inverter will be operated in the GC mode such that the power could be delivered into the ac grid. On the other hand, if the renewable energy is smaller than the load requirement, the bi-directional inverter will be operated in the PFC mode such that the ac source could supply power to the dc bus. The PV cell produces output current I is given by

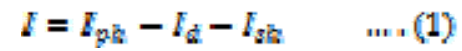

Where $I_{p h}$ is the Photon current, $I_{d}$ is the diode current and $I_{s h}$ is the shunt current. Fig 1 shows the equivalent circuit and characteristic of $\mathrm{i}-\mathrm{v}$ curve of solar cell. The net current $I$ is obtained from the photo current Iph and the diode current Id [5].
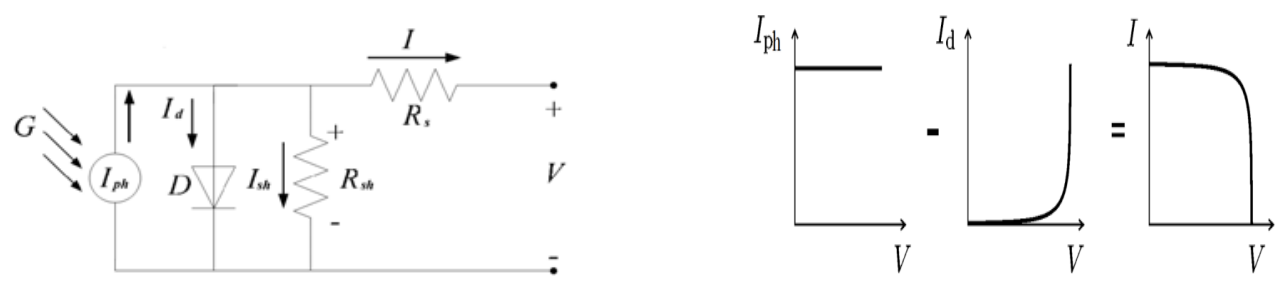

Fig: 1 Equivalent circuit \& i-v characteristic of solar cell 


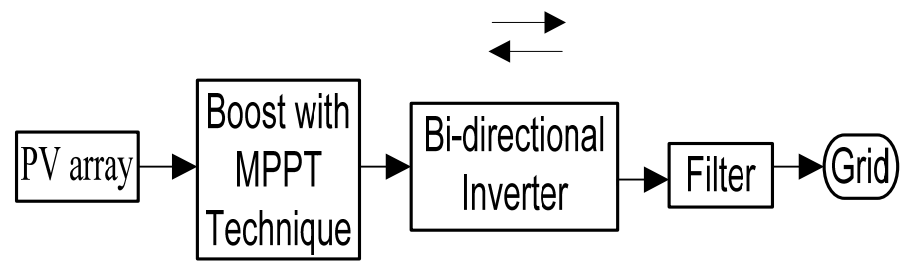

Fig: 2 Configuration of a Grid connected PV system with boost converter

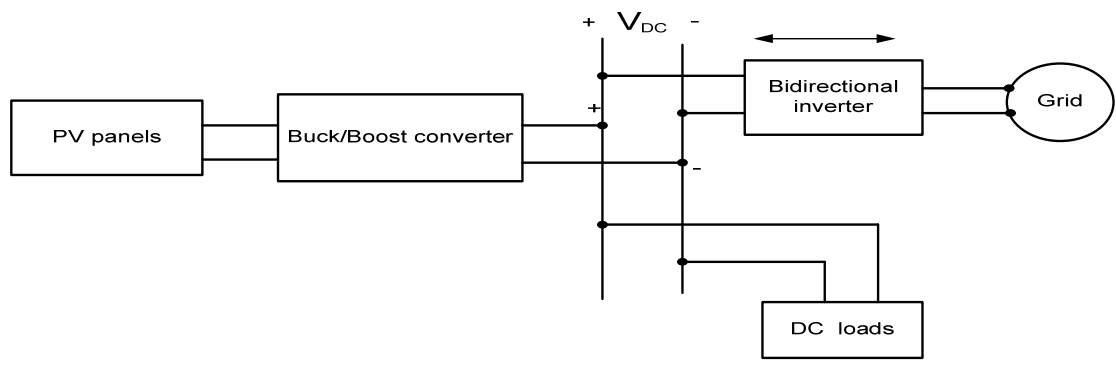

Figure. 3 Configuration of a Grid connected PV system with Buck/ boost converter

Figure 2 shows the PV output is connected to Boost converter with MPPT boosted voltage is connected to DC bus for utilization of DC loads, then excess of power is fed to grid via bidirectional inverter. In case of Buck/Boost with MPPT,it can be operated in both modes like whenever PV output voltage is lower than the DC bus voltage it acts as boost converter otherwise it acts as buck converter shown in figure 3 .

\section{BOOST CONVERTER}

The boost converter is shown in Fig. 4. In boost converter, the output voltage is higher than the input voltage hence the name "boost" converter. When the Switch is closed inductor stores energy in the form of magnetic field like $\mathrm{V}_{\mathrm{L}}=\mathrm{V}_{\mathrm{S}}$ during DT period. When the Switch is open the voltage across the inductor is $\mathrm{V}_{\mathrm{L}}=\mathrm{V}_{\mathrm{S}}-\mathrm{V}_{0 \text {. during }}$ T period shown in fig. 5 [5]

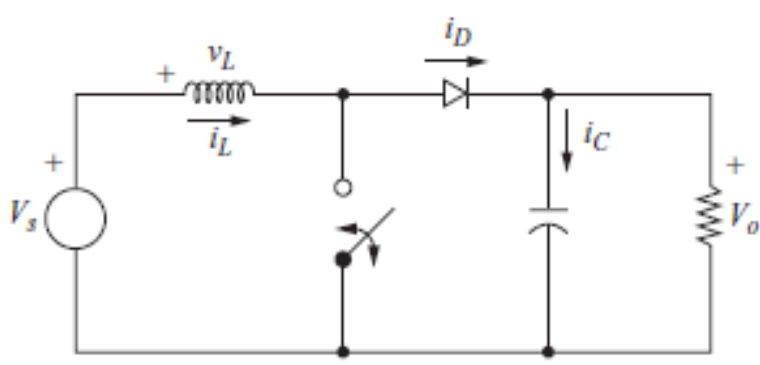

Fig: 4 The Boost converter

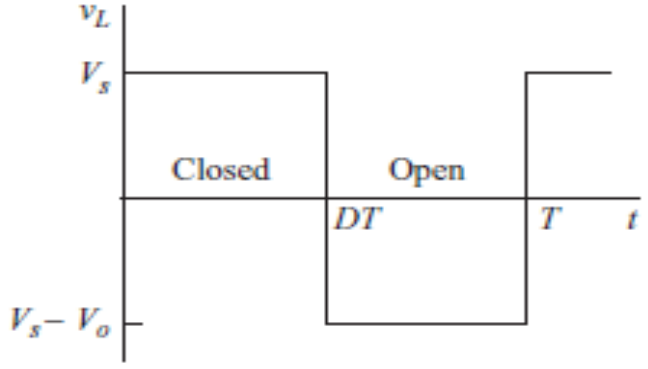

Fig: 5 Voltage across the inductor during ON and OFF time

\section{BUCK/BOOST CONVERTER}

In the DC distribution system, the input voltage for the converter is PV panel voltage $\left(\mathrm{V}_{\mathrm{pv}}\right)$ and the output voltage is DC bus voltage $\left(\mathrm{V}_{0}\right)$. If the PV panel voltage $\left(\mathrm{V}_{\mathrm{pv}}\right)$ is more than DC distribution system voltage $\left(\mathrm{V}_{0}\right)$, the converter should be operated in buck mode and the power semiconductor switch $\mathrm{M}_{2}$ is kept turned off. If the PV panel output voltage is low during that time converter should be operated in Boost mode and the power semiconductor switch M1 is always in ON condition [1] as shown in figure6.

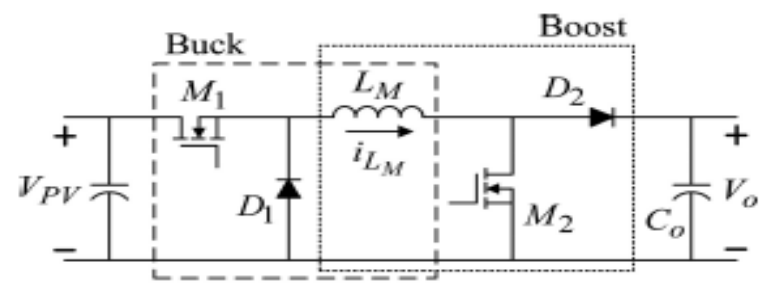

Fig. 6. Eqivalent circuit of Buck/Boost converter 
The critical control issue of the proposed circuit topology is the transition between buck and boost modes. If the PV-panel voltage and the dc-bus voltage are very close to each other, voltage and current fluctuations may occur due to malfunctioning of the power switches. To prevent the fluctuation problem, the mode transition scheme is implemented in this paper [1] . If the converter is operated in buck mode and $V_{\mathrm{PV}}$ is approaching $\mathrm{V}_{\mathrm{O}}$, the duty ratio of $\mathrm{M}_{1}$ will be increased to $100 \%$. Then, the operation mode is changed to boost mode and the duty ratio of $\mathrm{M}_{2}$ will be initially set to $0.5 \%$. On the other hand, when the converter is operated in boost mode and $\mathrm{V}_{\mathrm{PV}}$ is approaching $\mathrm{V}_{0}$, the duty ratio of $\mathrm{M}_{2}$ will be decreased to $0 \%$. During the mode transition, the input and output voltages of the MPPT will be very close. To avoid the over current fault and decrease the switching loss, the switch $\mathrm{M}_{1}$ is kept turned ON and the switch $\mathrm{M}_{2}$ is kept turned OFF in one perturbation period. This period is referred as the bypass mode. Then, the operation mode is changed to buck mode and the duty ratio of $\mathrm{M}_{1}$ will be initially set as $0.5 \%$.

\section{A. Maximum power point Tracking.}

The $\mathrm{P} \& \mathrm{O}$ method is adopted in this paper to obtain maximum power. The voltage and current parameters are necessary in the P\&O method to calculate PV-panel power. In the calculation of PV-panel power, the operation mode of the developed MPPT should be determined first. When the MPPT is operated in buck mode, the output current is continuous and is equal to the inductor current $\mathrm{I}_{\mathrm{LM}}$. Therefore, the output voltage $\mathrm{V}_{0}$ and the inductor current $\mathrm{I}_{\mathrm{LM}}$ can be employed to determine the power. If the MPPT is operated in boost mode, the input current will be continuous and equals inductor current $\mathrm{I}_{\mathrm{LM}}$. Hence, the power is calculated via the PV-panel voltage $\mathrm{V}_{\mathrm{PV}}$ and the inductor current $\mathrm{I}_{\mathrm{LM}}$. Due to the wide input voltage range, a large perturbation with a low input voltage will result in a high current spike under heavy load condition, while a low perturbation with a high input voltage might weaken the power response and the MPPT will determine a wrong maximum power. For applying to the wide input voltage range, the MPPT will be perturbed with step size $10-15 \mathrm{~V}$ and $1.3 \%$ duty ratio during a P\&O period. [1].

\section{IV.BIDIRECTIONAL INVERTER}

The proposed bidirectional inverter is a full-bridge configuration, as shown in Fig. 7,

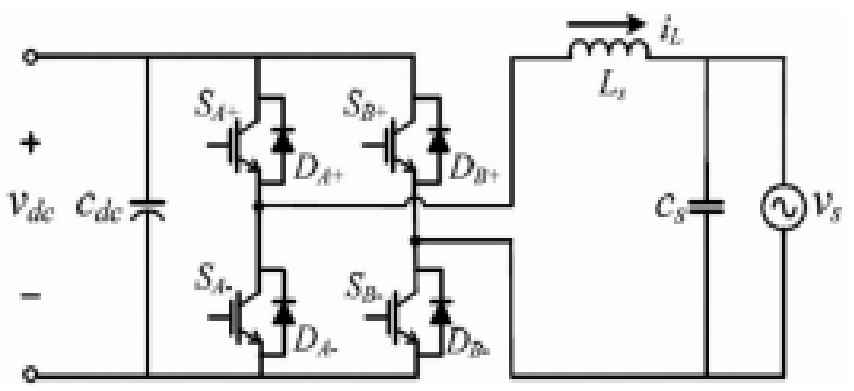

Fig:7 Bidirectional inverter with LC filter

A single-phase full-bridge bidirectional inverter is modelled in this study. The IGBT is used as power electronic switch as it can handle very large power, which is suitable for the solar system. In the developed grid connected (GC) inverter model unipolar switching scheme has two switching states as outlined in Table 1. The PWM inverter output waveform is then filtered to produce a sinusoidal AC waveform.

Table 1. Switching States of 1-Ø Full-Bridge Inverter

\begin{tabular}{|c|c|c|c|}
\hline $\begin{array}{c}\text { Switching } \\
\text { State }\end{array}$ & ON switch & OFF Switch & O/p Voltage \\
\hline 1 & SA+,SB- & SA-,SB+ & + Vdc \\
\hline 2 & SA-,SB+ & SA+,SB- & -Vdc \\
\hline
\end{tabular}

\section{RESULT ANALYSIS}

The performance of designed controller has been verified through simulation of closed loop inverter with boost and Buck/Boost converter. Simulation analysis has been carried out for the bidirectional inverter is shown in Figure $2 \& 3$ in MATLAB SIMULINK platform. The parameters used for the simulation are given in Table. 2

Table 1 System Parameters

\begin{tabular}{|c|c|c|c|}
\hline Specifications & Value & Component & Value \\
\hline DC Voltage $\left(\mathrm{V}_{\mathrm{dc}}\right)$ & $400 \mathrm{~V}$ & DC capacitor $\left(\mathrm{C}_{\mathrm{dc}}\right)$ & $3.3 \mathrm{mF}$ \\
\hline AC Voltage $\left(\mathrm{V}_{\mathrm{s}}\right)$ & $220 \mathrm{~V}$ & Inductor $\left(\mathrm{L}_{\mathrm{s}}\right)$ & $10 \mathrm{mH}$ \\
\hline Switching Frequency $(\mathrm{Fs})$ & $10 \mathrm{KHz}$ & Output Power $\left(\mathrm{P}_{0}\right)$ & $3 \mathrm{KW}$ \\
\hline
\end{tabular}



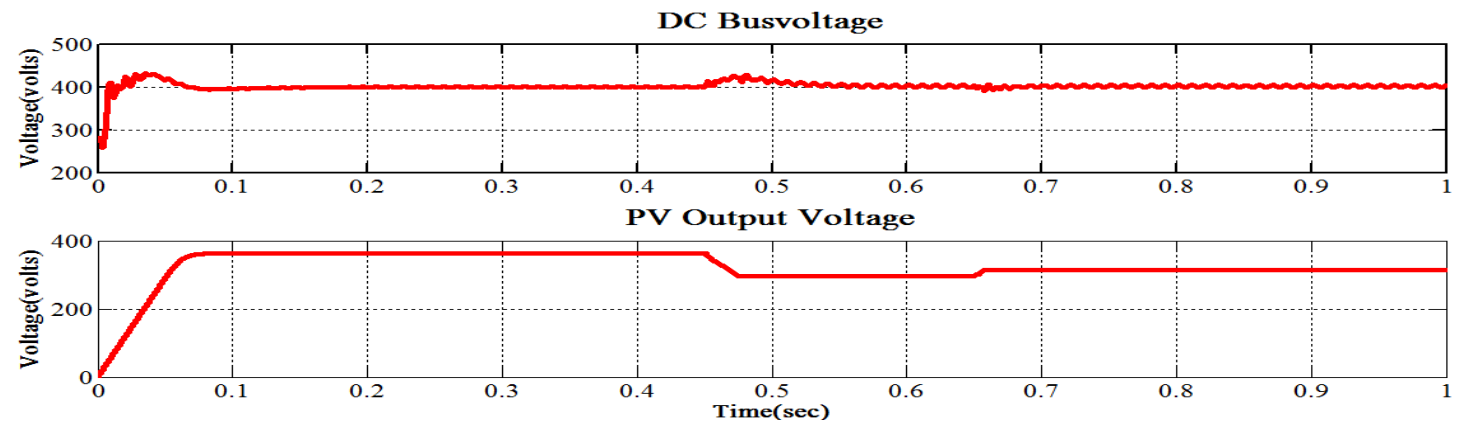

Figure. 8 Simulation results of Boost converter.

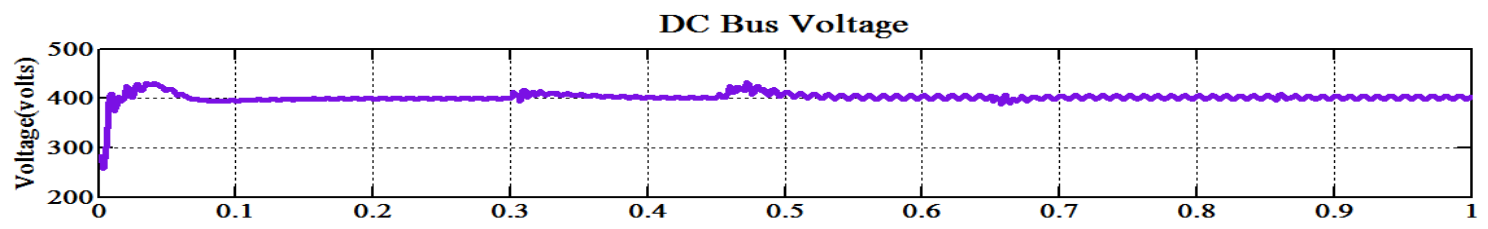

PV Output Voltage

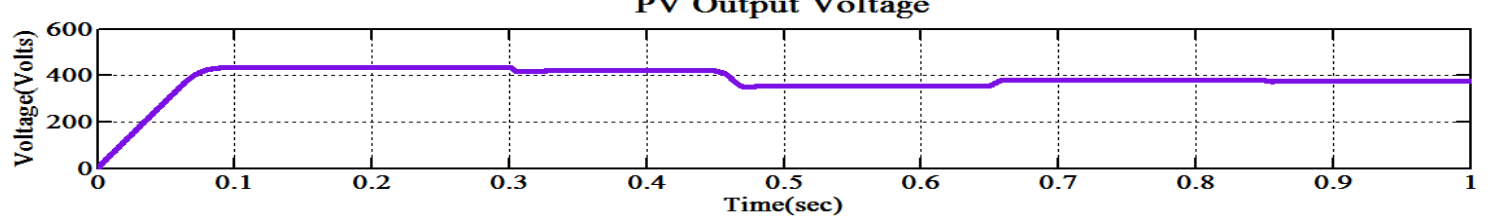

Figure. 9 Simulation results of buck/Boost converter.

Figure 8 shows the simulation of result for boost DC-DC converter for different PV output voltages always less than the DC bus voltage, but in case of figure 9 shows the PV output voltage higher than the DC bus voltage from 0 to 0.45 sec after that PV output voltage lower than the DC bus voltage but DC bus voltage remains constant in all the situations. Figure 10 shows the simulation of result for transient response of bidirectional inverter. Initially the inverter is operating in rectifying mode, feeding a resistive load in DC distribution system. At $t=0.3 \mathrm{sec}$, the PV source is turned on, to check the feasibility of the bidirectional converter in grid connected mode. It has been observed that a step change in power from $400 \mathrm{~W}$ to $500 \mathrm{~W}$ is given to bidirectional inverter. The inverter current is adjusted to a new value within 1 power cycle and DC bus voltage has come to steady state within 0.08 seconds. It can be observed that the grid current is out of phase by $180^{\circ}$ in inverter mode. As the bidirectional converter is connected to single phase utility, $2^{\text {nd }}$ harmonic component in DC bus voltage, $3^{\text {rd }}$ harmonic content in source current have been observed.

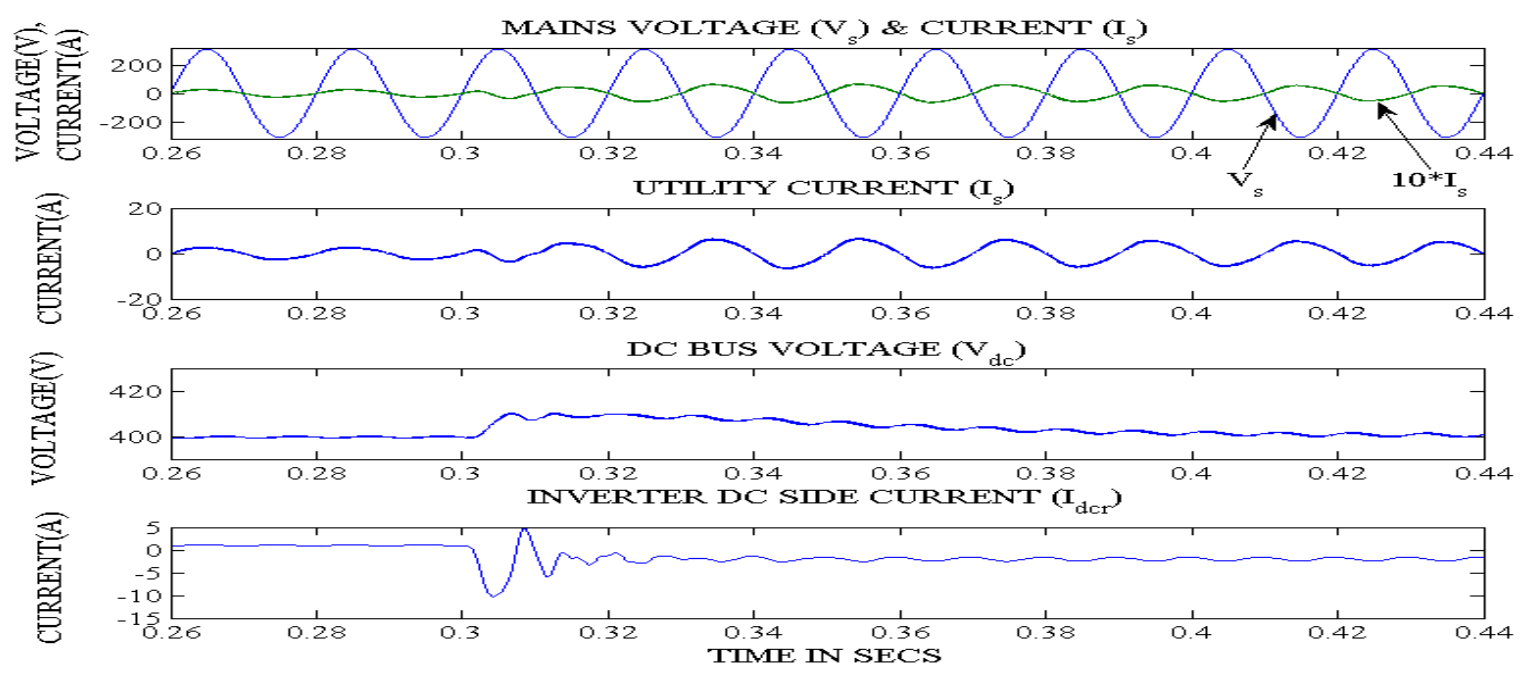

Figure. 10 simulation results of bidirectional inverter with PV source turned on 
To evaluate the feasibility of MPPT algorithm, the MPPT is initiated at $t=0.45 \mathrm{sec}$ as shown in figure.10. As the load is of $400 \mathrm{~W}$ and PV generation is of $2.9 \mathrm{KW}$, the excessive amount of power of $2.5 \mathrm{KW}$ is fed back to mains grid through bidirectional inverter. As the power flown through the bidirectional converter increased, the voltage ripple of the converter is also increased. It is because the power flow rate is more than the power density of the capacitor. The voltage ripples can be reduced by using bigger capacitance, however increase in capacitance might cause poor dynamic performance of the converter. During transient period, the DC voltage $\left(\mathrm{v}_{\mathrm{dcr}}\right)$ increases before settling back to reference value due to the regulative action taken by the voltage controller. From figure.11 there is no noticeable harmonic distortion in the line current during transient period.

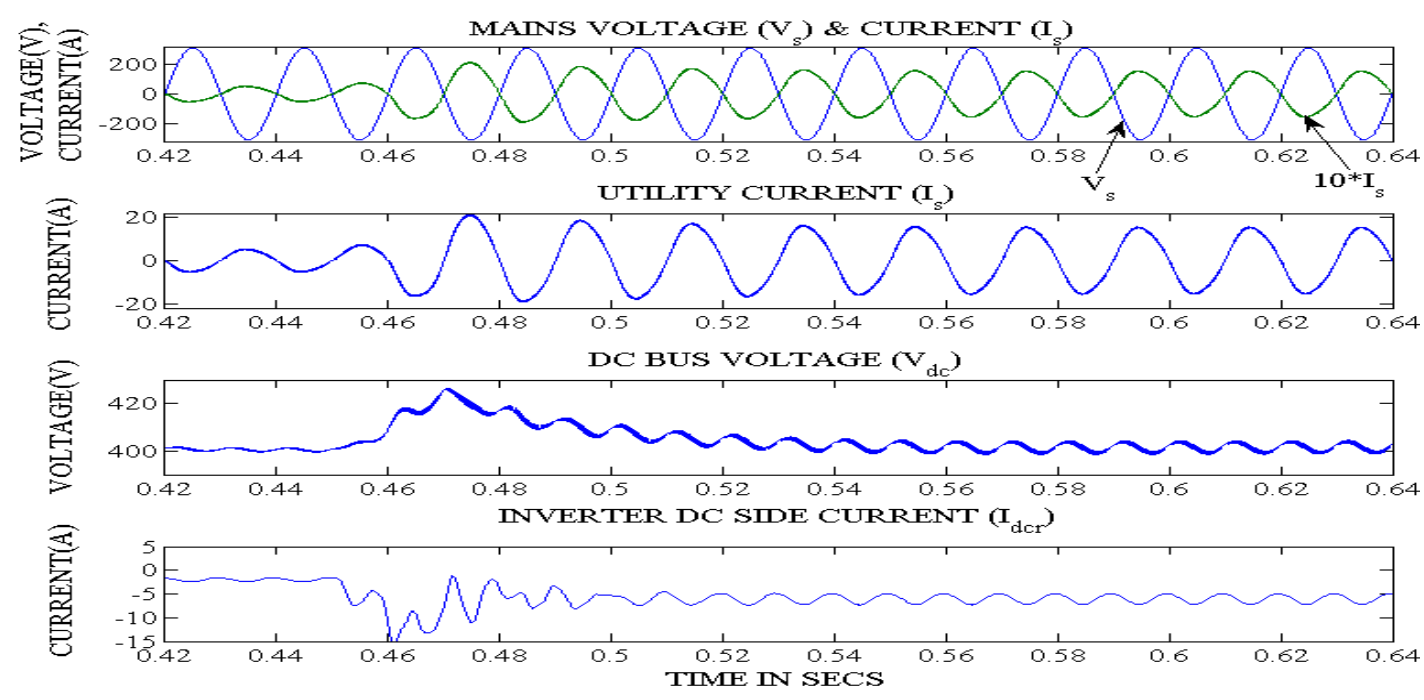

Figure 11 simulation results of bidirectional inverter with MPPT turned on

Partial shading of some panels in PV string not only reduces the output of panels, but also total power generated by PV string reduces. Figure.12 shows the simulation results of bidirectional converter with step change of irradiation from $1000 \mathrm{~W} / \mathrm{m}^{2}$ to $800 \mathrm{~W} / \mathrm{m}^{2}$ for one panel at $\mathrm{t}=0.65 \mathrm{sec}$. It has been observed that, the MPPT algorithm able to track new maximum power point.

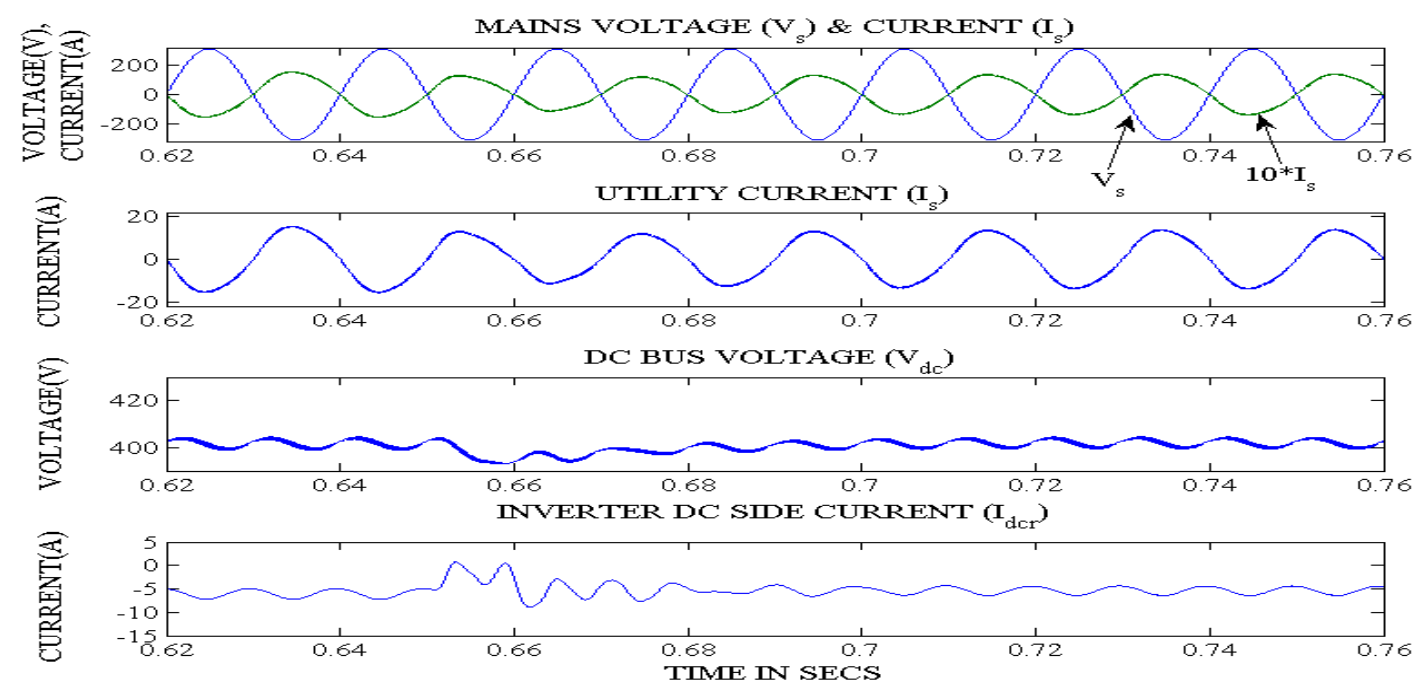

Figure 12 simulation results of bidirectional inverter with Step change in irradiation on one Panel

It is clear from the simulation results that the proposed predictive control scheme is working efficiently in both grid connected and rectifier modes. 


\section{CONCLUSION}

In this paper, a single phase bidirectional inverter with Boost \& Buck/Boost converter with MPPT has been simulated. With the help of Boost converter always boost up the PV output voltage but in space applications always boost converter is not good because PV output voltage is more than DC bus voltage. In such type of applications use Buck/Boost DC-DC converter. The utility interface converter must inject power (generating mode) to mains grid under excessive power conditions in dc distributions system and it has to draw power (rectifying mode) from the mains grid when power deficit occurs in the dc distribution system. This process has been done by bidirectional inverter and obtained simulated results with MATLAB Simulation.

\section{ACKNOWLEDGMENT}

This research is sponsored by means of the Science \& Engineering Research Board under grant "Empowerment and Equity opportunities for Excellence in Science”, No SB/EMEQ-322/2014, Dairy No. SERB/F/344/2015-16 dated 14.05.2015.

\section{REFERENCES}

[1] M. Srikanth, S. Tarakalyani and Dr. Poonam Upadhyay "CONTROL OF DC DISTRIBUTION SYSTEM WITH SINGLE PHASE UTILITY INTERFACE” International Conference on Recent Trends in Engineering, Science \& Technology(ICRTEST)2016.Proceedings by Elsevier Energy Procedia.

[2] D. Salomonsson, L. Soder and A. Sannino, “An adaptive control system for a dc microgrid for data centers,” IEEE Trans. on Industry Applications, vol. 44, Nov. 2008, pp. 1910-1917.

[3] T.-F Wu, H.-S Nein, C.-L Shen and T.-M Chen, "A single-phase inverter system for PV power injection and active power filtering with nonlinear inductor consideration,” IEEE Trans. on Industry Applications, Vol. 41, No. 4, pp. 1075-1083, July-August 2005.

[4] T.-F. Wu, S.-A. Wang, C.-L. Kuo and K.-Y. Lee, "Design and implementation of a push-pull phase-shifted bi-directional inverter with a dsPIC controller," Proceedings of the IEEE PEDS 2009, pp. 728-733.

[5] Marcelo Gradella Villalva, Jonas Rafael Gazoli, and Ernesto Ruppert Filho. "Comprehensive Approach to Modeling and Simulation of Photovoltaic Arrays” -IEEE Transactions on power electronics, vol. 24, no. 5, May 2009.

[6] M. Srikanth, S. Tarakalyani and Dr. Poonam Upadhyay "Grid Connected Single-Phase Bidirectional Inverter with MPPT 4. Tracker" International Electrical Engineering Journal (IEEJ), Vol. 6 (2015) No. 5, pp. 1898-1904, ISSN 2078-2365.

[7] M. Srikanth, S. Tara Kalyani, Poonam Upadhyay "Voltage Oriented Control Applied to a 3phase Bidirectional Inverter for Grid Connected PV System” I J C T A, 10(5) 2017, pp. 799-806 @ International Science Pres. 